transformation, a more limited and experimentally controllable aspect of variation, is discussed by Kilham; his article interprets and clarifies many of the phenomena that seemed insoluble puzzles in the 1930 's. A similar valuable awareness of the history of the subject is shown in the article on the polyome virus by Eddy; Stewart also discussed this group of viruses, and both articles stress the relevance of these studies to contemporary ideas on cancer causation. Warren discusses the relationship between the viruses causing measles, distemper and rinderpest.

There are two articles on the mechanisms by which viruses multiply and by which hosts resist this multiplication-Darnell and Eagle on polio and Smorodintsev on general aspects of the problem in animals and man.

One-third of the volume is more purely physical. Brakke describes the technique of density gradient centrifugation and the precautions that must be taken to get sharp separation when the differences in density or diameter are small. Klug and Caspar explain lucidly the evidence that $\mathrm{X}$-ray methods give about the architecture of crystalline or quasicrystalline viruses. They claim that uniformities in the manner in which sub-units are assembled are beginning to emerge; but it still seems likely that much of this uniformity is introduced by the experimenter's preference for stable viruses as objects for intensive study and that stability depends on the particle being assembled in accordance with a limited number of sound engineering designs.

The editors are to be congratulated on the uniformly high quality of these reviews. A future number might usefully include an article explaining how evolution is supposed to work in viruses, for the concept is invoked by several authors in this number.

N. W. Pirie

\section{THE NATURAL WEALTH OF SCOTLAND}

\section{Natural Resources in Scotland}

Symposium at The Royal Society of Edinburgh, 31 st October to 2nd November 1960. Pp. ix +796 . (Edinburgh: Scottish Council (Development and Industry), 1961.) $105 s$.

7 HIS sumptuous volume is the record of a threeday symposium held at the Royal Society of Edinburgh, during October 31-November 2, 1960, organized by the Committee on Natural Resources of the Scottish Council under the chairmanship of Mr. L. A. Elgood, a leader of Scotland's banking and industry. With the widespread use of tape-recorders there is now no difficulty in making a word by word record of the whole proceedings of a conference. But the technique of good public speaking is quite different from the technique of good writing, and a conference reproduced in extenso in print is liable to seem inordinately verbose. Had the proceedings of this conference been carefully edited and reduced to about one-third the length, the value would have been immeasurably increased. By the time one has read for the twentieth time, "Your Grace, my Lords, Ladies and Gentlemen", or some variant thereof, one is grateful to the speaker who comes rudely and abruptly to his subject-matter, and who does not even say, "I must be brief ..." In like manner the volume closes with the Chairman's enigmatical words, "At 3 o'clock I was unhappy. At 4 o'clock I am very happy".
The 808 quarto pages with about three-quarters of a million words contain what may best be called a stocktaking of the present position. The first day, and so the first third of the book, was devoted to "Basic Resource Facts"-including soils, minerals, water, fish and wildlife. A lively debate on a proposed National Atlas for Scotland ended the day's proceedings, but bad editing makes it difficult to follow. What is meant by the constant references to maps at $1: 1$ mile and $1: 2$ miles ? But behind the discussion there seems to be the age-old Scottish mistrust that anything good for the whole of Britain could emanate from England. It is admitted that the collaboration of the Scottish Department of Health in the magnificent work of the Maps Office of the Ministry of Housing and Local Government has broken down these ten years, so that tragically many maps can only be prepared for England and Wales.

The second day was devoted to the "Utilisation of Resources", with a special emphasis on agriculture and forestry-perhaps one should say the relative claims of agriculture and forestry, which one speaker suggested resolved itself into forestry in the uplands, agriculture in the lowlands. There was criticism of vague arguments, and pleas for a 'little more scientific thought', but few of the discussions produced clear-cut objectives.

Although an American contribution on "Outdoor Recreation Potential as a Natural Resource" introduced an outside point of view, in the discussion each speaker seemed to have a personal hobby-horse: small-boat sailing, training of gardeners, factory visits in the Highlands to attract tourists on wet days, and a dozen others, but no overall picture emerged.

The chairman for the third day was Sir Edward Appleton, and the topic "Resource Administration and Development". Since neither is possible without the requisite man-power, the proceedings were opened with papers dealing with human resources, and education. Migration of Scots overseas has given place to migration of Scots to south of the border, yet a larger proportion of the residents of Scotland (8 per cent in 1951) were born elsewhere than is the case in England and Wales (5.8). Are the best brains leaving and less-able immigrants coming in ? Both the Chairman and Mr. Kyd, late registrar-general, are clearly puzzled by the facts they record. In some strange way it seems that the country has never adjusted itself to the conditions which followed the break-up of the clans in 1746. Taking $£ 3,000$ as the cost of bringing a youth to maturity at the age when he will become an emigrant, Kyd ventures the statement that Scotland loses a minimum of $£ 60,000,000$ a year by the emigration of its people. Lord Fleck, a Glaswegian himself. whose leadership of industry has been essentially outside Scotland, sums it up by declaring to his fellow Scots: "Ye must be born again". It is far from clear whether this would be achieved in the new University of Inverness which was proposed in a later paper.

It is difficult in a brief review to do justice to the vast range of material contained in this volume. But it is unco-ordinated and one puts it down with the vaguely unhappy feeling that life in Scotland itself is unco-ordinated, that a great people from a country with many and varied resources-of which natural beauty is by no means the least-are fumbling to find their right line of development and their right niche in the modern world. As one speaker said: "It is no use blaming England that our people prefer to go there". 